Arqueología y Sociedad,

№ 22, 2010

\title{
LA PROTECCIÓN CONTRA EL TRÁFICO DE BIENES CULTURALES
}

\author{
Carolina Cárdenas Oscátegui*
}

\section{Resumen}

El tráfico de bienes culturales se ha intensificado últimamente, vemos que nuestros bienes se comercializan y salen de nuestro país, siendo las excavaciones clandestinas, el robo sistemático en iglesias, museos, entre otros, los delitos más frecuentes. Desde este espacio tratamos de dar un marco general sobre la problemática existente y algunos planteamientos para la reducción del tráfico de bienes culturales desde la sociedad civil y en especial desde la Universidad.

\section{Palabras clave}

Patrimonio cultural de la Nación, patrimonio cultural, patrimonio cultural mueble, tráfico de bienes culturales, protección del patrimonio cultural.

\begin{abstract}
Traffic of cultural properties has intensified lately, we see that our patrimony are sold and leave our country, being clandestine excavations, the systematic theft in churches, museums, among others, the most common crimes. From here we try to give a general framework on the existing problems and some approaches for reducing the traffic of cultural property from civil society and especially from the university.
\end{abstract}

\section{Keywords}

Nation's cultural heritage, cultural heritage, movable cultural property, protection of the cultural heritage, illicit traffic of cultural property.

\footnotetext{
* Gestora Cultural. Egresada de la Maestría de Arte Peruano y Latinoamericano con mención en Gestión Cultural y Desarrollo de la Unidad de Postgrado de la Facultad de Letras y Ciencias Humanas de la Universidad Nacional Mayor de San Marcos. Miembro de ICOM-PERU. Responsable de Grupo Pro Arte y Cultura para el Desarrollo. Correo electrónico: caro_oscategui@hotmail.com
} 
Los mercados internacionales aunado a la pobreza, el analfabetismo, la pérdida de valores educativos y culturales ciudadanos son las principales causas para que el tráfico de bienes culturales continúe.

Con la pérdida de nuestro patrimonio no solo perdemos nuestros bienes materiales sino toda una herencia que no se puede cuantificar, los valores, la historia, la cultura de un pueblo no tienen valor económico, y eso es lo que sucede cuando se invade una zona arqueológica, se profana una tumba, se extrae objetos de los sitios arqueológicos, siendo imposible hacer las investigaciones en esa zona que nos de información sobre el proceso histórico cultural y social de los habitantes en un determinado momento.

\section{LEGISLACIÓN INTERNACIONAL}

Las primeras convenciones, protocolos y recomendaciones para la protección de los bienes culturales son emprendidas por la Organización de las Naciones Unidas para la Educación, la Ciencia y la Cultura - UNESCO, con la participación de diferentes países de todo el mundo, los que se denominarán en adelante "Estados miembros" y se establecen a partir del año 1954.

El primer documento que elabora UNESCO fue la Convención de la Haya denominada "Convención para la protección de los bienes culturales en caso de conflicto armado y reglamento para la aplicación de la convención, considera bienes culturales, cualquiera que sea su origen y propietario" el cual tiene sus dos protocolos firmados el primero el 14 de mayo de 1954 y el segundo el 26 de marzo de 1999. ${ }^{1}$

1 Seguidos a esta convención se elaboraron documentos más específicos para las naciones confortantes.

- Convención sobre las medidas que deben adoptarse para prohibir e impedir la importación, la exportación y la transferencia de propiedad ilícitas de bienes culturales - 1970. UNESCO 1970 y 1972

- Convención sobre la protección del patrimonio mundial cultural y natural - 1972.

- Convención sobre defensa del patrimonio arqueológico, histórico y artístico de las Naciones Americanas (Convención de San Salvador) - 1976.
La Convención de UNESCO de 1970 "Sobre las medidas que deben adoptarse para prohibir e impedir la importación, la exportación y la transferencia de propiedad ilícitas de bienes culturales", algunos de los países confortantes de esta Convención no se encuentran sujetas a toda la reglamentación de la norma. ${ }^{3}$

Lamentablemente el no haber ratificado el convenio por ciertos países imposibilita la recuperación de nuestros bienes culturales, asimismo la legislación varía de país en país, no constituyendo un delito contra el patrimonio cultural en algunos, que tienen la propiedad de piezas culturales.

Algunos museos en diferentes lugares del mundo tienen en su colección bienes culturales que han sido productos de saqueos, extracciones y robos que existieron desde el siglo XIX procedentes de culturas antiguas de Grecia, Egipto, Italia, existiendo también bienes precolombinos, entre ellos los peruanos.

- Convención para la salvaguardia del patrimonio cultural inmaterial - 2003. París, 17 de octubre de 2003.

- Convención sobre la protección y la promoción de la diversidad de las expresiones culturales - 2005.

- Convenio de UNIDROIT sobre los bienes culturales robados o exportados ilícitamente - 1995.

- Decisión № 588 - Sustitución de la Decisión 460 sobre la protección y recuperación de bienes del patrimonio cultural de los Países Miembros de la Comunidad Andina.

- Memorandums de entendimientos de Perú con diversos países.

2 UNESCO. Esta Convención entró en vigor el 24 de abril de 1972. Luego entró en vigor para cada Estado tres meses después de la fecha de depósito de su instrumento, salvo en los casos de notificaciones de sucesión, en los cuales la entrada en vigor se produce en la fecha en la que el Estado asume la responsabilidad de dirigir sus relaciones internacionales.

3 UNESCO. Compendio de Convenciones y recomendaciones de la Unesco sobre la protección del patrimonio cultural. 1983. pp 104. Estado de ratificaciones ( $\mathrm{R}$ ), aceptaciones (A) y adhesiones (a) al 31.05 .86

4 Ver portal de lista de países ratificantes de Convención de UNESCO. En: <www. portal.unesco.org/ la/convention.asp?language $=\mathrm{S} \& \mathrm{KO}=13039>$. $[22 \mathrm{de}$ julio de2010, 10:30 p.m.] 
Tenemos como ejemplos el friso del Partenón en el Museo Británico de Londres; el Templo de Dendur, monumento egipcio del año 15 a.C. que fue trasladado de Egipto a EEUU en 1965 e instalado en 1978 en el Metropolitan Museum of Art de EEUU en el ala Sackler, que además cuenta con una importante colección de arte egipcio.

Si bien es cierto algunas instituciones en el mundo adquirieron legalmente hace muchos años o son parte de una herencia dejada por antiguos propietarios, sería bueno que se devolviera los bienes a su lugar de origen, al margen de la propiedad de estos, demostrándose de esta manera la cooperación y el fomento de la valoración de las identidades de los pueblos.

Es importante señalar que el tener la carga de prueba que señale la propiedad del bien, es una de las razones importantes para afrontar largos procesos judiciales debido a que su compra fue legítima, contando con sus respectivos comprobantes de pago, o por herencia.

\section{La Legislación Nacional}

\section{La Constitución Política del Perú}

El Perú cuenta con instrumentos normativos para la protección de nuestro patrimonio cultural, una de ellas es la Constitución Política del Perú del 1978, el cual contaba con 4 artículos referentes a la protección del patrimonio cultural. Después de la reforma de nuestra constitución en el 1993, se redujo en un solo artículo, que es el siguiente:

"Artículo 21: Los yacimientos y restos arqueológicos, construcciones, monumentos, lugares, documentos bibliográficos y de archivo, objetos artísticos y testimonios de valor histórico, expresamente declarados bienes culturales, $y$ provisionalmente los que se presumen como tales, son patrimonio cultural de la Nación, independientemente de su condición de propiedad privada o pública. Están protegidos por el Estado.

La ley garantiza la propiedad de dicho patrimonio. Fomenta conforme a ley, la partici-

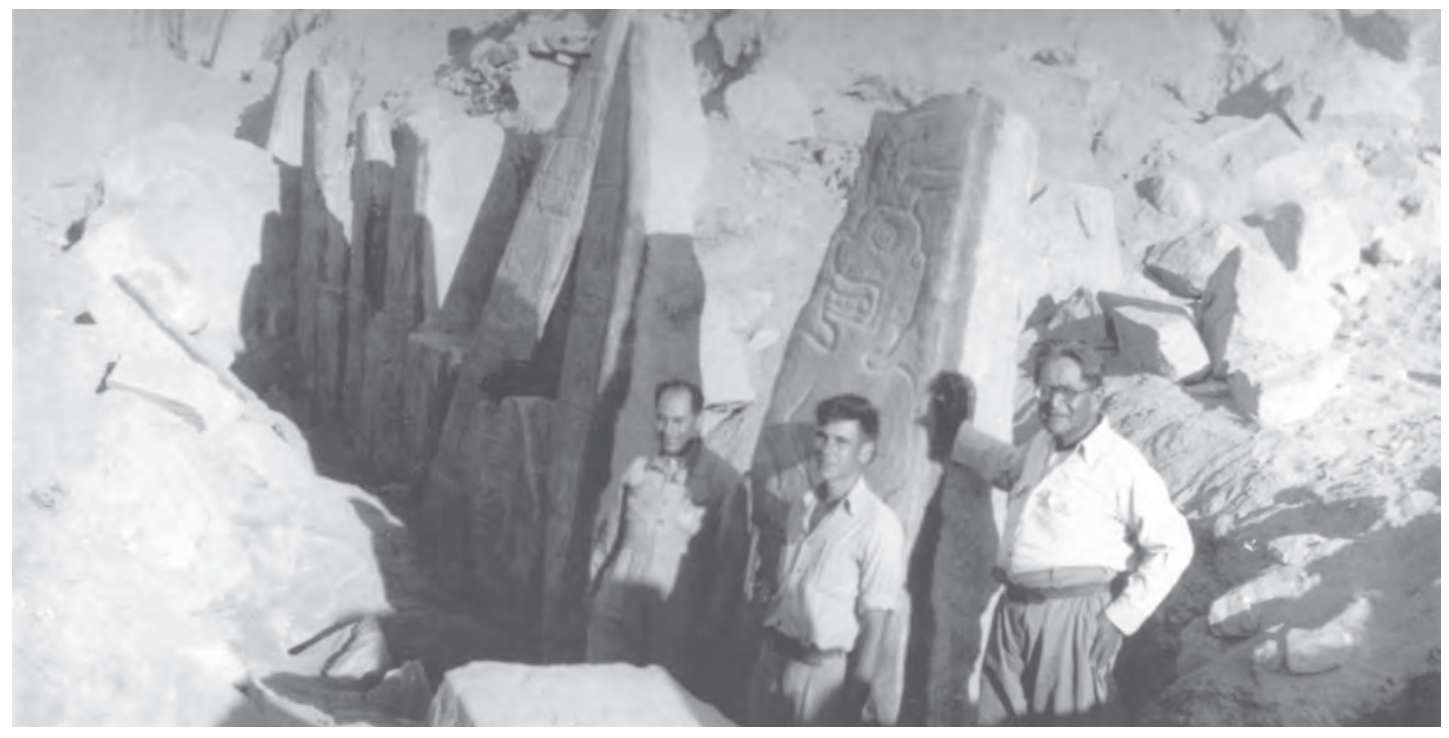

Julio C. Tello, considerado el Padre de la Arqueología Peruana, contribuyó con sus investigaciones a formar las bases de nuestra identidad cultural. Siendo congresista presentó proyectos de ley a favor de la protección del patrimonio cultural. Aquí Tello se encuentra en Sechín, Casma, junto con su colaborador Mejía Xesspe. Fotografía: Cortesía Museo de Arqueología y Antropología, UNMSM. 
pación privada en la conservación, restauración, exhibición y difusión del mismo, así como su restitución al país cuando hubiere sido ilegalmente trasladado fuera del territorio nacional." (Constitución Política del Perú, 1993)

\section{El Código Penal Peruano}

Presenta un título compuesto por seis artículos que sancionan los delitos contra el patrimonio cultural, entre las cuales el artículo 228 se refiere a la sanción penal correspondiente a la persona que cometiera los delitos detallados en el siguiente acápite contra los bienes culturales prehispánicos que estén o no declarados como patrimonio cultural de la Nación:

Art. 228․- El que destruye, altera, extrae del país o comercializa bienes del patrimonio cultural prehispánico o no los retorna de conformidad con la autorización que le fue concedida, será reprimido con pena privativa de libertad no menor de tres ni mayor de ocho años y con ciento ochenta a trescientos sesenta y cinco días-multa.

En el caso que el agente sea un funcionario o servidor público con deberes de custodia de los bienes, la pena será no menor de cinco ni mayor de diez años.

De igual manera, en el artículo 230, se detalla las sanciones penales frente a la persona que comete los delitos contra el patrimonio cultural pero en este caso de la época hispánica, y la diferencia en este artículo, es que los bienes culturales deben ser declarados patrimonio cultural de la Nación y expresa:

Artículo 230: El que destruye, altera, extrae del país o comercializa, sin autorización, bienes culturales previamente declarados como tales, distintos a los de la época prehispánica, o no los retorna al país de conformidad con la autorización que le fue concedida, será reprimido con pena privativa de libertad no menor de dos ni mayor de cinco años y con noventa a ciento ochenta días-multa."
Si bien contamos con el código penal, es necesario que se den penas y reparaciones civiles de acordes al daño causado.

\section{Los Bienes Culturales}

Se entiende como bienes culturales a las manifestaciones culturales realizadas por el hombre, con una "importancia, valor y significado paleontológico, arqueológico, arquitectónico, histórico, artístico, militar, social, antropológico, tradicional, religioso, etnológico, científico, tecnológico o intelectual, sea expresamente declarado como tal o sobre el que exista la presunción legal de serlo. Dichos bienes tienen la condición de propiedad pública o privada con las limitaciones que establece la ley 28296" (artículo II del título preliminar de la Ley 28296); éstos se clasifican en bienes materiales muebles, que son aquellos que pueden ser tocados y transportados (tenemos como ejemplo: un huaco retrato de los moches, un manto paracas, una momia del señor de Sipan); bienes materiales inmuebles, que s0on aquellos que sí se pueden tocar pero no pueden ser transportados (tenemos como ejemplo a la zona arqueológica de Chan Chan, las casonas que corresponden al Centro Histórico de Lima, los petroglifos de checta, entre otros) y los bienes inmateriales, que son las expresiones intangibles; aquí tenemos como ejemplo: el pisco peruano, la marinera, el seviche, entre otros. ${ }^{5}$

5 La Ley General del Patrimonio Cultural de la NaciónLey 28296, en su artículo V sobre la Protección señala:

Los bienes integrantes del Patrimonio Cultural de la Nación, independientemente de su condición privada o pública, están protegidos por el Estado y sujetos al régimen específico regulado en la presente Ley. El Estado, los titulares de derechos sobre bienes integrantes del Patrimonio Cultural de la Nación y la ciudadanía en general tienen la responsabilidad común de cumplir y vigilar el debido cumplimiento del régimen legal establecido en la presente Ley.

El Estado promoverá la participación activa del sector privado en la conservación, restauración, exhibición y difusión de los bienes integrantes del Patrimonio Cultural de la Nación y su restitución en los casos de exportación ilegal o cuando se haya vencido el plazo de permanencia fuera del país otorgado por el Estado. 


\section{Problemática}

Los saqueos y excavaciones clandestinas en las zonas arqueológicas se han incrementado en estos últimos años, siendo las piezas peruanas extraídas unas de las mejores cotizadas en el mercado internacional, así como también los hurtos de bienes culturales de iglesias, conventos y otros de objetos litúrgicos, lienzos de los siglos XVIII, y otros, de agrado de comerciantes, los cuales estarían haciendo el pedido a través de intermediarios, para que formen parte de sus respectivas colecciones. Los daños a Monumentos arqueológicos e históricos declarados patrimonio cultural por obras inconsultas, demoliciones, restauraciones sin autorizaciones respectivas por parte de privados, y otros, destruye su valor histórico y/o arqueológico.

Nuestros bienes culturales que forman parte de los monumentos en el Centro Histórico de Lima y otros del país se encuentran en estados que requieren apoyo para ser restaurados, éstos tienen una riqueza histórica y que si se planteara proyectos de conservación, puesta en valor en estas zonas, tendríamos una buena imagen como capital y nos compararíamos con otras metrópolis.

Las invasiones promovidas por traficantes de tierras, contribuyen a que la población menos favorecida, en busca de viviendas, invadan zonas arqueológicas, destruyendo también monumentos arqueológicos sin darle la importancia debida y jugando con la necesidad del ciudadano.

Debido a la situación social y económica de nuestro país, personas que viven en condiciones de pobreza extrema no tienen el acceso a la información sobre educación y cultura, no cuenta con los servicios básicos esenciales, menos aún conoce de leyes. Lo único que conocen sobre su patrimonio cultural es a través de los relatos, his-

Para el cumplimiento de las disposiciones de la presente Ley, el Instituto Nacional de Cultura, la Biblioteca Nacional y el Archivo General de la Nación, son los organismos que se encargaran del registro, declaración y protección del Patrimonio Cultural de la Nación, el INC velara por el patrimonio arqueológico e histórico, la biblioteca por el patrimonio bibliográfico y el Archivo por el patrimonio documental. torias, leyendas, que sus abuelos y padres transmitían a sus hijos, por lo que era la única forma de continuar sus costumbres; de esta forma, los ciudadanos sabían que las zonas arqueológicas de su distrito eran importantes porque sus ancestros se lo contaron; es de esta manera como ellos reconocen que si tienen un valor cultural

Lamentablemente, esta condición de vida obliga a ciertos grupos, y en especial a los jóvenes, que son los más vulnerables a negociaciones que vulneran nuestro patrimonio para poder ganar una suma de dinero de forma fácil y rápida se dedican a la excavación clandestina (huaqueo), trafico de tierras (invasiones), robo a iglesias y otros, y en el momento que se presenta la oportunidad de saquear una zona arqueológica e invaden zonas arqueológicas, venden las piezas saqueadas y los ingresos recolectados será para satisfacer sus necesidades básicas de alimentación, vestido, entre otros.

Con la problemática anteriormente citada se tiene la pérdida de nuestro patrimonio, una herencia que no se puede cuantificar, los valores, la historia, la cultura de un pueblo no tienen valor económico, y eso es lo que sucede cuando se invade una zona arqueológica, se profana una tumba, se extrae objetos de los sitios arqueológicos, siendo imposible hacer las investigaciones en esa zona que nos de información sobre el proceso histórico cultural y social de los habitantes en un determinado momento.

Entonces, la falta de protección en zonas arqueológicas de Lima y Provincias y el desconocimiento de la importancia del sitio, hacen que las zonas arqueológicas continúen siendo depredadas, monumentos sigan siendo dañados, bienes muebles extraídos o robados produciendo así daños irreversibles a nuestro patrimonio cultural.

\section{Excavaciones Arqueológicas Clandestinas}

Las excavaciones arqueológicas clandestinas se realizan a los sitios arqueológicos, que se encuentren o no debidamente registrados, señalizados y delimitados. 
De acuerdo con el listado de sitios arqueológicos publicados en la página web del INC, muestra 4542 sitios arqueológicos declarados patrimonio cultural de la Nación hasta el 17 de febrero de 2006.

Cada declaratoria conlleva previamente haber realizado una investigación arqueológica, y solicitar las autorizaciones respectivas.

Las exploraciones e investigaciones de todos los proyectos arqueológicos para todas las zonas arqueológicas en el Perú, son elaboradas a través de particulares; estos proyectos duran varios meses, y luego de esto, se debe presentar un informe final de la investigación realizada. ${ }^{6}$

Artículo 5ํ- La investigación arqueológica en el Perú, es de interés social y científico; corresponde al Estado su regulación y promoción a través del Instituto Nacional de Cultura. Es objeto de la investigación arqueológica el estudio de los restos materiales y de su contexto cultural y ambiental de las sociedades que existieron en el territorio nacional, así como su protección, conservación y difusión. (Reglamento de Investigaciones arqueológicas, 2000)

Asimismo parte del trabajo de señalización y delimitación por Ley también compete a los gobiernos locales y regionales, que cuentan con presupuestos para desarrollar este tipo de proyectos, así como el catastro de las áreas que tienen inscripciones registrales.

Art 82 Inc. 12 Promover la promoción y difusión del patrimonio cultural de la $\mathrm{Na}$ ción, dentro de su jurisdicción, y la defensa y conservación de los monumentos arqueológicos, históricos y artísticos, colaborando con los organismos regionales y nacionales competentes para su identificación, registro, control, conservación y restauración. (Ley Orgánica de Municipalidades)

Lamentablemente, algunos municipios en vez de invertir sus presupuestos en la protección

6 Ver texto completo del Reglamento de Investigaciones Arqueológicas - INC. del patrimonio cultural, realizan obras inconsultas, dañando monumentos tanto arqueológicos como históricos, sin autorización del Ente Rector.

A la ya debilitada problemática, las invasiones promovidas por traficantes de tierras, contribuyen a que la población menos favorecida, en busca de viviendas, invadan zonas arqueológicas, destruyendo también monumentos arqueológicos que serían una buena fuente de ingresos, si se supiera trabajar a nivel del turismo.

\section{El registro de bienes culturales}

Se ha implementado una oficina ${ }^{7}$ especial para el registro patrimonial informatizado de bienes integrantes del patrimonio cultural de la nación, trabajo que se inicia, y que es un paso para poder contar con toda el registro de bienes culturales en el Perú, pero a pesar de las acciones realizadas para tener un registro completo de bienes culturales, es indispensable que la ciudadanía se involucre y registre los bienes, esto con una adecuada difusión y promoción sobre el registro de bienes culturales y su importancia al ciudadano. Según UNESCO, una de las mejores formas de proteger los bienes culturales es de acuerdo a un registro e inventario adecuado.

En el artículo 17 de la Ley 28296 trata so-

\section{Registro Nacional de Bienes}

15.1 Créase el Registro Nacional Patrimonial Informatizado de Bienes Integrantes del Patrimonio Cultural de la Nación a cargo del Instituto Nacional de Cultura que tiene por objeto la centralización del ordenamiento de datos de los bienes culturales de la Nación, en el marco de un sistema de protección colectiva de su patrimonio a partir de la identificación y registro del bien.

15.2 Todo bien que se declare integrante del Patrimonio Cultural de la Nación será inscrito de oficio en el Registro Nacional de Bienes Integrantes del Patrimonio Cultural de la Nación, generándose una Ficha Técnica en la que constará la descripción pormenorizada y el reconocimiento técnico del bien, y un Certificado de Registro del organismo competente que otorga a su titular los beneficios establecidos en la presente Ley. Tratándose de bienes de propiedad del Estado integrantes del Patrimonio Cultural de la Nación deben ser registrados en el SINABIP (Sistema de Información de Bienes de Propiedad Estatal). 


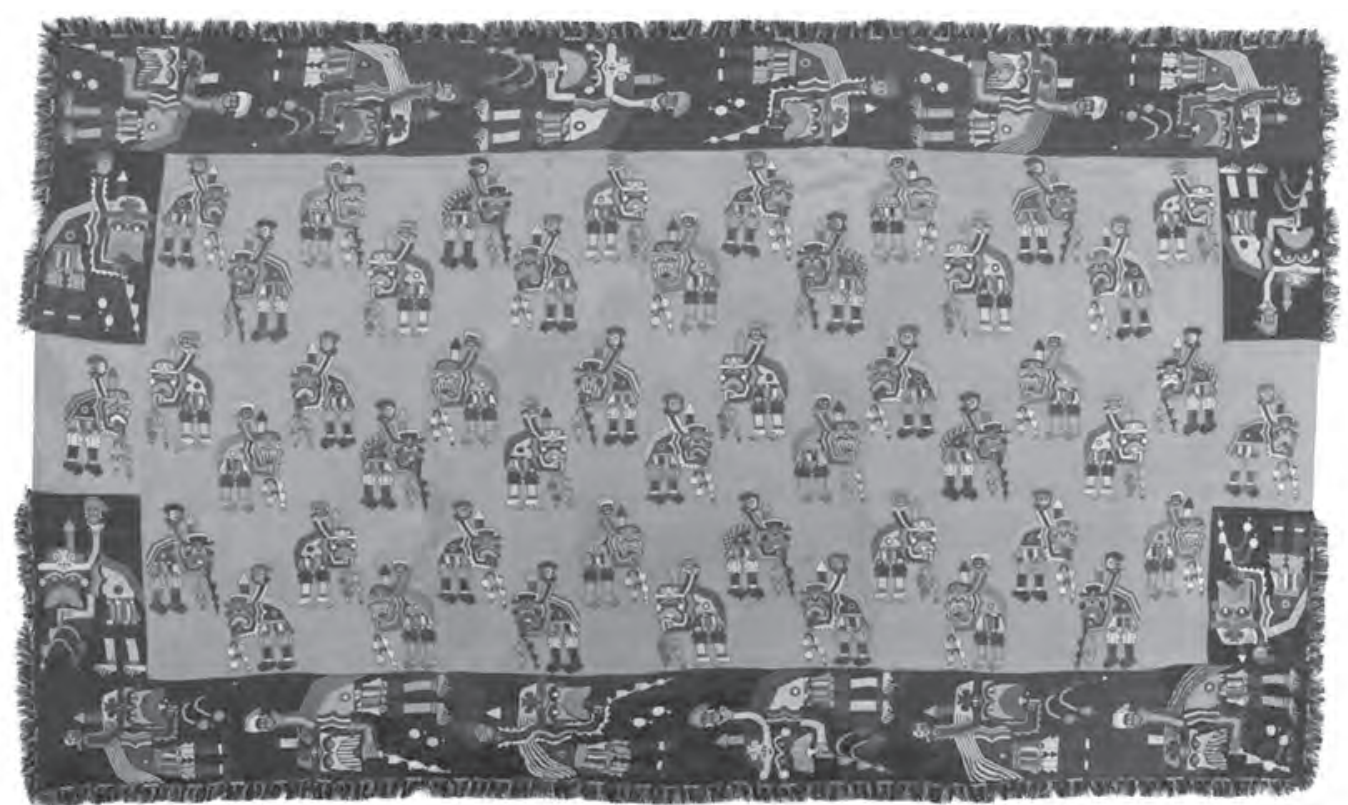

Los Mantos Paracas (0 a.c. a 700 d.c) son una de las maravillas del Perú, este manto se conserva en el MNAAHP. Según la Lista Roja todos los textiles peruanos corren peligro y necesitan protección, y es en el saqueo y destrucción de los fardos funerarios donde perdemos valiosa información de nuestro pasado. Fotografía: Daniel Giannoni - ICOM Perú.

bre la Obligatoriedad del Registro: se expresa: "El propietario de un bien que es integrante del Patrimonio Cultural de la Nación está obligado a solicitar ante el organismo competente el registro de los mismos".

Por otro lado, los bienes procedentes de excavaciones no autorizadas (huaqueos o saqueos), en zonas arqueológicas, que han salido del país por medio del contrabando y sin un registro (ficha técnica con los detalles y especificaciones del bien) y mucho menos una Resolución Directoral Nacional, que lo declare patrimonio cultural de la Nación, es sumamente difícil conocer el paradero de estas piezas.

Toda esta situación imposibilita la identificación de la pieza cultural, siendo difícil su recuperación y posterior repatriación a nuestro país.

El desconocimiento de la población sobre la importancia de los bienes culturales

Como ya habíamos señalado anteriormente debido a la situación social y económica de nues- tro país, existen un sector de la población que viven en condiciones de pobreza extrema, los cuales no tienen el acceso a los servicios básicos esenciales, menos aún conoce de leyes. Es ahí donde se inicia el problema, el no conocer sobre la importancia de la protección de su patrimonio cultural.

\section{Orígenes de saqueos de bienes culturales}

En el manual de Unesco para la prevención del tráfico ilícito de bienes culturales, David Walden, señala: "el comienzo de los saqueos y pillajes de una nación a otra, explica que a lo largo de la historia, los objetos y obras de arte siempre fueron apreciados como formas de expresión de las culturas que han creado. Por ejemplo durante las campañas napoleónicas en Italia, Europa y el norte de África, científicos, artistas, investigadores e historiadores formaban parte de lo que se conocía como la comisión científica y artista. Esta comisión seleccionaba sistemáticamente y transportaba, los principales tesoros culturales de estos países hacia Francia." 
Los orígenes de este delito en el Perú, se remonta a la época de la conquista momento en la cual se inicio los saqueos de nuestro legado inca, extrayéndose tesoros, siendo los más cotizados los objetos producidos con metales y piedras preciosas.

La primera ley sobre el tema se encuentra en el Decreto Supremo N ${ }^{\circ} 89$ del 2 abril de 1822 , suscrito por Torre Tagle por orden de Bernardo de Monteagudo que resuelve:

Art 1. Se prohíbe absolutamente la extracción de piedras minerales, obras antiguas de alfarería, tejidos y demás objetos que se encuentren en las huacas, sin expresa y especial licencia del gobierno, dada con alguna mira de utilidad pública.

Art.2 El que contraviniere el artículo anterior, incurrirá en las penas de perdimiento de la especie, sea poco o mucho su valor, la que se aplicará al Museo Nacional, y a más de 1000 pesos de multa aplicados a los fondos destinados a la instrucción pública. Los administradores de aduana y comandantes de resguardo, quedan encargados de velar la observancia de este decreto bajo su responsabilidad.

A partir de esta ley, los gobiernos dictan leyes cada vez más específicas; es así que en leyes posteriores se estaría incluyendo los bienes culturales procedentes de excavaciones en templos, fortalezas; asimismo se haría la declaratoria de monumentos, y existían solicitudes para la excavación en zonas arqueológicas.

Entonces, podemos inferir que desde el año 1822, la población peruana tenía conocimiento de que las excavaciones clandestinas y los hallazgos producto de las mismas serían un delito y por ende sujetos a una sanción.

\section{Los Mercados internacionales}

El mercado internacional es un espacio en el que se oferta objetos culturales precolombinos, entre ellos los peruanos, donde comerciantes y otros con poder político y económico compran y revenden estas piezas, a casas de subastas, museos, galerías y/o para ser mostradas como parte de sus colecciones exhibidas en instituciones importantes.

Los comerciantes y otros se valen de intermediarios que hacen el contacto con los huaqueros que depredan las zonas arqueológicas que aún no han sido declaradas, registradas, señalizadas, demarcadas e inscritas en registros públicos. Asimismo, este círculo de tráfico gusta también de bienes culturales provenientes de hurtos sacrílegos de lugares donde reine la falta de medidas de seguridad.

La existencia de un mercado internacional que cotiza en altos precios los bienes culturales peruanos que luego son revendidos por precios más altos a colecciones privadas, galerías, subastas, entre otros, perjudicando al Estado peruano demanda piezas precolombinas, entre ellas las peruanas, que tienen una gran cotización motivada por coleccionistas con mucho dinero y poder, que se dedican a planificar y obtener piezas que van en desmedro de la nación peruana.

Según el Consejo Internacional de Museos (ICOM), y la policía internacional Interpol, en Múnich "El tráfico ilegal de objetos históricos y de arte del acervo cultural de Perú está alcanzando "niveles inusitados" y deberá ser frenado con ayuda internacional." 8

El director general del ICOM, Julien Anfruns, opina que "Europa es el centro del mercado negro para la venta ilegal de los bienes culturales y los países más afectados de perder importantes y valiosas piezas de su patrimonio histórico son los latinoamericanos".

Entre 2004 y 2006 se descubrieron ventas ilícitas de más de 5.000 bienes culturales y naturales peruanos y las excavaciones clandestinas en sitios arqueológicos han aumentado, así como los saqueos y robos en iglesias y museos, según cifras del ICOM.

8 Diario El Comercio. "Tráfico de piezas históricas peruanas alcanza niveles nunca vistos". <http://www. elcomercio.com.pe/ediciononline/html/2009-01-13/ trafico-piezas-historicas-peruanas-alcanza-niveles-nunca-vistos-segun-expertos.html>. [6 de Junio de 2009. 22:00 horas]. 
De la etapa prehispánica son especialmente tejidos, metales, cerámica, fósiles y restos humanos, mientras que de la colonia y del período posindependentista los más requeridos son objetos etnográficos, pinturas, esculturas, platería, numismática, mobiliario y estampas.

"El tráfico ilícito de bienes culturales en el mundo genera 6 mil millones de dólares por año en el mundo, ocupando el tercer lugar en el ranking mundial de mercados ilegales.”.(Secretaría de Cultura de la Nación de Argentina).

La Dra. Ruth Shady9 señala que “... es más fácil para los traficantes adquirir piezas de los museos que comprarlas a los excavadores clandestinos. Los robos se han multiplicado, hace dos décadas desaparecieron 5000 piezas del Museo Nacional de Antropología y Arqueología y la prensa ha informado de robos recientes en el Museo Regional de Ica, en el Museo de la Universidad de la ciudad de Trujillo, en el museo de sitio de Cerro Colorado, etc. Algunas de las sustracciones han estado relacionadas con los asesinatos de conocidos coleccionistas y comerciantes, como Emil Bernal, vinculado con el Saqueo Sipan) Muñoz-Najar 2007) o de los poseedores de piezas saqueadas como Raul Apesteguia en Lima (O Brien y Pierina 2006)”

\section{LOS TIPOS DE COMERCIALIZACIÓN}

\section{Mercados virtuales}

Actualmente, la manera más común y rápida de comercialización de bienes culturales es a través de páginas web tales como Ebay, Mercado Libre, pariscampusanuncios, precolumbianart4sale, todocolección., liveauctionners, entre otros. Si bien es cierto que las políticas de estas páginas son de libre comercio, y contiene políticas de salvaguarda al patrimonio cultural de los países

9 Ruth Shady Solís. "Política Cultural en el Perú y la Situación del Patrimonio Arqueológico". International Journal of South Amecican Archaeology 2: 6-17(2008). <http://www.scribd.com/doc/7338024/Politica-Cultural-en-el-Peru-y-la-Situacion-del-Patrimonio-Arqueo$\operatorname{logico}>$. previa demostración de la propiedad, y una política de la empresa a la privacidad de la identidad de sus clientes, no paralizan sus subastas en tiempo real, ni entregan los nombres de los que ofertan o compran estas piezas hasta no contar con una orden judicial. Lo cual es difícil de cumplir en nuestro país debido a que muchas piezas saqueadas o hurtadas están fuera del país sin registro, imposibilitando la paralización de estas subastas a nivel electrónico.

\section{Casas de subastas}

Otra de las formas de comercialización es a través de casas de subastas con colecciones y clientes importantes; tenemos como ejemplo la casa de subastas Sotheby's, casa Christie's, Casa Gaia, Casa Binoche, Dorotheum, todas ellas son casas de reconocido prestigio, que hacen la venta final a coleccionistas de gran

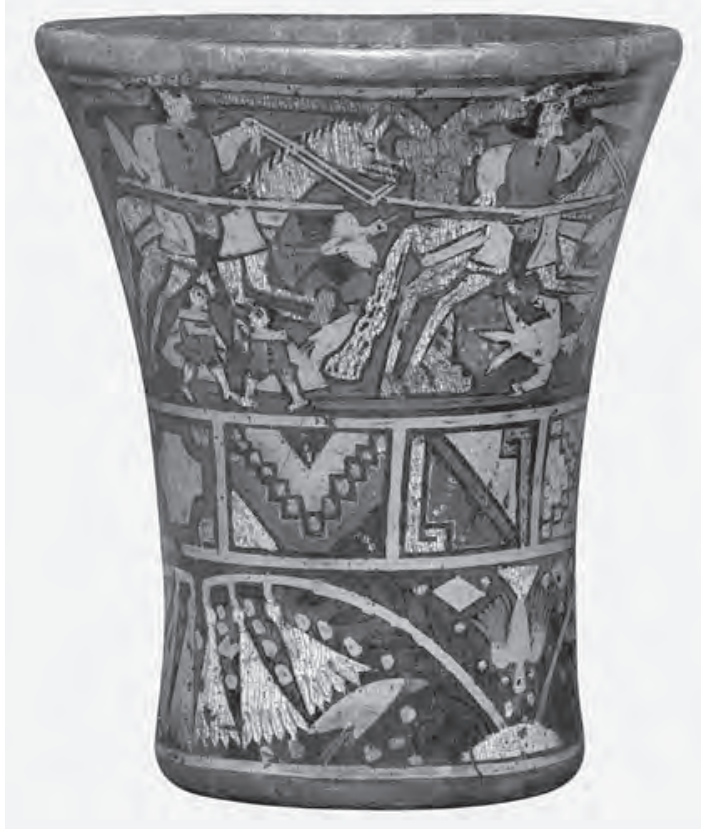

Vaso ceremonial de madera con decoración policroma proveniente de la Sierra Sur. Datan de la época Inca. La mayoría de Keros se encuentra en colecciones particulares lo que dificulta su control y facilita la venta en las casas de subastas. Fotografía Daniel Giannoni - ICOM Perú. 
poder económico, y político, y se encargan de realizar la venta con sus respectivas facturaciones o documentos para avalar la venta. Es decir, con todas las formalidades del caso.

\section{Casas de subastas Sotheby's y Christie's de Nueva York}

En mayo del 2007, la prensa limeña y en especial el diario El Comercio, Miguel Vivanco redactó un artículo titulado "La triste pérdida de nuestra herencia" publicado el 09.12.07, que habla sobre el caso de la venta en las Casas de subastas Sotheby's y Christie's de Nueva York, en las que se ofertaba bienes prehispánicos peruanos. A pesar de que el gobierno peruano había solicitado la paralización de la venta, las casas no la detuvieron: la casa Christie's de Nueva York subastó 24 lotes de piezas arqueológicas prehispánicas por más de 180.000 mil dólares, y no se sabe acerca de lo que paso con 11 lotes adicionales de piezas. Según el diario El Comercio, "el cónsul del Perú en Nueva York, Helí Peláez Castro, había manifestado que la cancillería, en coordinación con el Instituto Nacional de Cultura (INC), podría contratar los servicios de una prestigiosa firma de abogados para defender la propiedad de nuestro patrimonio".

\section{Actores de la problemátic sobre bienes culturales}

El huaquero o saqueador, es la persona que comete el delito de remoción, alteración de yacimientos arqueológicos, que no están declarados, registrados o señalizado, y que no tiene vigilancia ni seguridad, se vale de un grupo de personas para cometer el atentado; éstos al obtener los objetos culturales los venden a los intermediarios perdiéndose así el legado histórico por completo. "A los huaqueros o saqueadores sólo les interesan las piezas que pueden comerciar y las cortan para tener un negocio más lucrativo sin saber que el patrimonio nos pertenece a todos", (Instituto Nacional de Antropología y Pensamiento Latinoamericano de Argentina; 2009)"10

El ladrón, es la persona que comete el delito de Hurto, sustrayendo de Iglesias, monumentos, museos, y otros, bienes culturales que luego son comercializados a los intermediarios, han existido casos en que los ladrones al necesitar dinero rápido, venden las piezas en oro a fundidore, pérdiendose por siempre cualquier posibilidad de recuperar nuestro patrimonio.

El intermediario, es la persona conocedora y con conexión con el comerciante internacional, es el que cotiza, selecciona, ubica, investiga los posibles bienes culturales a traficar, coorganiza un plan para la sustracción o huaqueo; en fin, es un estratega en este comercio, dándose la opción de marketearse y tener una variada presentación ante personas que pueden comprar las piezas.

El comprador que comercia, es la persona que cuenta con poder adquisito sufienciente para comprar los bienes culturales y revenderlos a otros clientes de mayor potencial economico ubicados en el extranjero, y cuida que todo sea entregado en sus manos de la manera más formal, es decir, la venta debe ser hecha incluido constancias, certificados o documentos que acrediten que lo están obteniendo de manera legal. Muchas veces esta pieza tiene que haber pasado más de 3 dueños anteriores antes de llegar a ellos.

El comprador final, es la persona que compra el bien cultural que previamente ya tiene documentación legal, y éste puede conocer o no el grado de legalidad de la adquisición de la pieza, esta persona puede haber visto el bien subastado en algun portal de internet, en casas de subastas, en tiendas de coleccionistas, entre otros. Lo compra porque tiene la certeza de que lo que esta comprando es legal y sin problemas.

10 Ver más información. En <http://www.elestudiantedehistoria.blogspot.com $>$ [18 de julio de 2010]. 


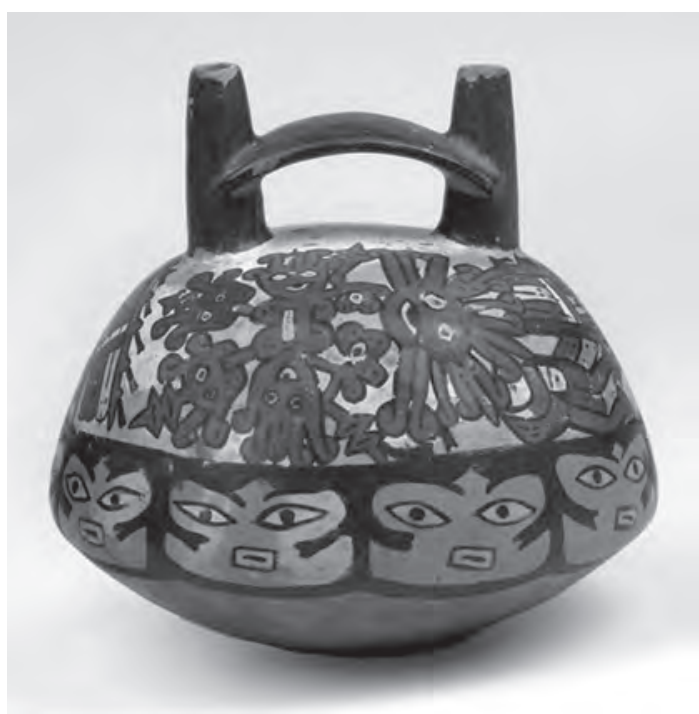

Los artesanos nazca se caracterizan por plasmar con talento exquisito su arte en la ceramica, textileria, entre otros. Asimismo las piezas de esta cultura son cotizadas a precios elevados en el mercado internacional, por lo que debemos estar siempre atentos para evitar el comercio ilícito. Fotografía: Daniel Giannoni - ICOM Perú.

\section{RutAS DE SALIDA DE BIENES CULTURALES}

\section{La ruta marítima}

La aduana ${ }^{11}$ marítima diariamente supervisa grandes cantidades de envíos de los agentes de aduanas y de serpost, a diversos lugares del mundo a través del mar, los trabajadores de aduanas hacen un exhaustivo control y realizan incautaciones no solo de bienes culturales sino de otros tipos de contrabando, que son camuflados en paquetes de diferentes envíos a través de esta ruta.

\section{La ruta aérea}

Una forma común de salida es a través del equipaje de los pasajeros antes de abordar el avión

\footnotetext{
11 De acuerdo al reglamento de la Ley general de Aduanas, "...la acción fiscalizadora se canaliza a través de tres etapas: La verificación física de la mercancía en el momento del despacho aduanero; La ejecución de auditorias a una muestra representativa de operadores de comercio exterior (Empresas, agencias de aduana, almacenes aduaneros, empresas de mensajería, etc.); La realización de operativos y patrullajes a nivel nacional a fin de reprimir el contrabando".
}

respectivo en el aeropuerto Jorge Chávez, haciéndolos pasar como un bien de uso frecuente; si bien es cierto, muchos extranjeros desconocen la pertenencia o no como patrimonio cultural, ya sea porque lo obtuvieron en una compra en mercados artesanales o en el mismo aeropuerto, el salir del país sin un certificado del INC o una verificación en el módulo hace que los agentes de seguridad del aeropuerto junto con la Policía Fiscal y un personal de INC retengan la pieza para determinar su pertenencia, dándose las respectivas sanciones administrativas o penales, en caso de pertenecer al patrimonio cultural de la $\mathrm{Na}$ ción "... sólo el año pasado se realizaron más de 11,000 verificaciones inmovilizando 1,235 bienes e impidiendo su salida del país y cada mes se realiza un aproximado de 600 verificaciones y 30 retenciones" (Gaceta cultural del INC: 2009)

\section{El Correo Postal}

Mediante este tipo de envío rápido y efectivo, de los bienes culturales, es una de las formas que no detecta a los traficantes, porque algunas veces dejan el envío con documentos falsos que imposibilitan su captura. Aquí el personal de Serpost con Agentes de Aduanas, hacen la revisión previa para localizar las piezas culturales. "Serpost Lima centraliza a todos los Serpost de provincias que son destinados al exterior, y es en esa planta donde se realiza el trabajo minucioso de análisis. El destino frecuente de estos envíos ilícitos es Estados Unidos (45\%). En 2008, el pico de capturas disminuyó a 132 en comparación del 2007". (Gaceta Cultural del INC, 2009)

\section{Fronteras terrestres}

Lo accidentado de nuestra geografía, la inexistencia de una demarcación y limitación física en todo el territorio nacional, el escaso personal de seguridad en fronteras, la falta de equipos y medios tecnológicos contra el contrabando, hacen que nuestras fronteras entre Perú-Bolivia, PerúEcuador, Perú-Chile, Perú-Colombia, Perú-Brasil, sean zonas vulnerables para el tráfico de bienes culturales, siendo difícil la desarticulación de estas redes acentuadas por años. 


\section{AgENTES DE PROTECCIÓN DEL PATRIMONIO CULTURAL}

A continuación les presentamos información ubicada en los portales institucionales de los siguientes agentes:

INTERPOL, es una organización de policia internacional, con 187 países miembros, su sede esta en Lyon-Francia, y es la que tiene la administración de la base de datos de objetos de arte robados, recuperados; y las últimas ediciones de los carteles de las obras de arte más buscadas de todo el mundo ${ }^{12}$.

Según lo expresado por el Instituto Nacional de Cultura en su Gaceta Cultural de abril del 2009 una vez obtenida la información por medio de comunicaciones de organizaciones internacionales, cadena de noticias, $\mathrm{u}$ otros el Instituto Nacional de Cultura, coordina con INTERPOL, Ministerio de Relaciones Exteriores, u otros, para la paralización de la comercialización, venta u exhibición, en casas de subastas, museos u otros en el exterior.

UNESCO, La Organización de las Naciones Unidas para la Educación, la Ciencia y la Cultura (UNESCO), es una Agencia del Sistema de las Naciones Unidas que nació en Londres el 16

12 Solo en el 2007, habrían circulado más de diez millones 800 mil mensajes, que son 30 mil mensajes cada día, y bastan solamente algunos segundos para transferir las informaciones. El CD-ROM disponible de estos objetos, está destinado a la policía y los servicios aduaneros, a los museos, casas de subastas, anticuarios, coleccionistas y, en general, a los aficionados al arte, y ofrece información sobre unos 31.500 objetos artísticos y bienes culturales, como por ejemplo, pinturas, esculturas o tapices, que pueden localizarse con diversos criterios de búsqueda: el título de la obra, el nombre del artista, la descripción de la obra, sus dimensiones o la técnica empleada para su realización, este $\mathrm{CD}$ ayudara a identificar las obras de arte y descubrir casos de tenencia ilícita de las mismas.

Pronto en este año 2009, de acuerdo a su pagina web Interpol implementará un acceso en línea a su base de datos de obras de arte robadas, en la que tendrán acceso en tiempo real a las informaciones registradas en dicha base de datos, todos sus usuarios autorizados, dificultando así la reventa de objetos culturales robados. de noviembre de 1945, como consecuencia del nuevo orden internacional establecido después de la Segunda Guerra Mundial. Sus primeros objetivos buscaban contribuir a la reconstrucción de las actividades educativas, científicas y culturales de los países de Europa después de la guerra, introduciendo el concepto de protección del patrimonio cultural como un aporte para su preservación.

La finalidad de la UNESCO es contribuir a la paz y seguridad mundial, promoviendo la colaboración entre las naciones mediante la educación, las ciencias, la cultura y las comunicaciones.

Es una organización de cooperación técnica e intelectual que, a través del dialogo y la concertación, promueve la búsqueda de las mejores alternativas de solución para cada una de las realidades nacionales, de acuerdo con sus propias especificidades. Entra en la esfera de su competencia todo aquello que involucre la vida del espíritu, contribuyendo mediante su acción, a crear condiciones, proponer ideas, transferir conocimientos, movilizar competencias, voluntades y siempre que sea posible, también recursos.

ICOM, es una organización internacional de museos y profesionales de museos que se ha comprometido a la conservación, el mantenimiento y la comunicación a la sociedad del patrimonio natural y cultural del mundo, presente y futuro, tangible e intangible, la ONG nace en 1946 y mantienen relaciones formales con la UNESCO ${ }^{13}$.

13 ICOM. As a not for profit organisation, ICOM is financed primarily by membership fees and supported by various governmental and other bodies.LLLLLLleva a cabo parte del programa de la UNESCO para los museos. Based in Paris (France), the ICOM Headquarters houses both the ICOM Secretariat and the UNESCO. ICOM Museum Information Centre . con sede en París (Francia), las casas de la sede del ICOM, tanto la Secretaría del ICOM y la UNESCOP UNESCO-ICOM de Información Museográfica Centro. The 26,000 members of ICOM in 139 countries participate in the national, regional and international activities of the organisation: workshops, publications, training, twinning program- 
CAN, es una Comunidad formada por Ecuador, Perú, Colombia, Bolivia unidas voluntariamente con el objetivo de alcanzar un desarrollo más acelerado, más equilibrado y autónomo, mediante la integración andina, suramericana y latinoamericana. Se propone avanzar en la profundización de una integración integral que contribuya de manera efectiva al desarrollo humano sustentable y equitativo para vivir bien, con respeto por la diversidad y las asimetrías que aglutine las diferentes visiones, modelos y enfoques y que sea convergente hacia la formación de la Unión de Naciones Suramericanas (Unasur). Entre sus objetivos están: Promover el desarrollo equilibrado y armónico de los Países Miembros en condiciones de equidad, mediante la integración y la cooperación económica y social; Acelerar su crecimiento y la generación de ocupación; Facilitar su participación en el proceso de integración regional, con miras a la formación gradual de un mercado común latinoamericano. Propender a disminuir la vulnerabilidad externa y mejorar la posición de los Países Miembros en el contexto económico internacional; Fortalecer la solidaridad subregional y reducir las diferencias de desarrollo existentes entre los Países Miembros y Procurar un mejoramiento persistente en el nivel de vida de los habitantes de la Subregión.

Ministerio de Relaciones Exteriores, la Cancillería peruana tiene la responsabilidad de contribuir a la elaboración y ejecución de la Política Exterior del Estado, La Cancillería ha sido, históricamente, un factor de desarrollo y cohesión de la identidad nacional. La Cancillería está integrada por los funcionarios del Servicio Diplomático de la República, y por personal profesional especializado y técnico administrativo. ${ }^{14}$

mes, and the promotion of museums through (May 18, annuallyLos 26.000 miembros de ICOM de 139 países participan en las actividades nacionales, regionales e internacionales de la organización: talleres, publicaciones, capacitación, programas de hermanamiento, y la promoción de los museos a través de Internacional Día de los Museos (18 de mayo de cada año).

14 Ministerio de relaciones Exteriores. Plan de Política
Instituto Nacional de Cultura, es un organismo público descentralizado dependiente del Ministerio de Educación, creado el 9 de marzo de 1971, su finalidad es afirmar la Identidad Nacional mediante la ejecución descentralizada de acciones de protección, conservación y promoción, puesta en valor y difusión del patrimonio y las manifestaciones culturales de la Nación para contribuir al desarrollo nacional con la participación activa de la comunidad y los sectores público y privado. La Dirección de Defensa del Patrimonio Histórico creada en el 2003, tiene como principales objetivos coordinar, tanto a nivel institucional como interinstitucional, las acciones de protección, defensa, recuperación y repatriación del patrimonio cultural de la Nación, Es a través de esta área que se realiza el peritaje de los bienes culturales que se encuentran en el extranjero y articula con la Procuraduría Pública Ad Hoc del INC a fin de que esta coordine las acciones judiciales necesarias para la recuperación de los bienes culturales

Las fiscalías especializadas en acciones vinculadas a la preservación del patrimonio cultural son la 5o Fiscalía Provincial de Prevención del Delito de Lima, que es la que realiza acciones de prevención antes que se realice el delito y la 45을 Fiscalía Provincial de Prevención del Delito de Lima, se encarga de interponer la denuncia penal correspondiente y las investigaciones ante la realización del hecho, y se encarga de concluir la investigación con una resolución fiscal que identifica al responsable e impone la sanción y lo remite al Juzgado para la continuación de la investigación a nivel judicial, que impondrá la pena y la reparación civil del inculpado

Cultural Exterior (RS 125-2003-RE) el cual contempla Políticas de Promoción Cultural, siendo la Subsecretaría de política cultural, el encargado de la coordinación con las embajadas del Perú en los países en que se encuentren las piezas culturales, con el INC, INTERPOL y otros a fin de gestionar las acciones necesarias para la repatriación de los bienes culturales peruanos. 


\section{La Lista Roja}

Tiene por finalidad proteger el patrimonio cultural en peligro, ayudando a los funcionarios de aduanas, policías, marchantes de arte, museos y coleccionistas a identificar los objetos de posible procedencia ilícita, esta recomienda a los eventuales compradores que se abstengan de efectuar cualquier transacción, a no ser que las piezas vayan acompañadas de un título de propiedad y un certificado de procedencia que prueben la legalidad de su origen. Asimismo, se exhorta a las autoridades pertinentes a que tomen las medidas precautorias habituales con los objetos de origen sospechoso, mientras se investiga más a fondo su procedencia. (ICOM, 2006) ${ }^{15}$

Propuesta de aCCIONES DE SENSIBILIZACión A LA COMUNIDAD POR PARTE DE LOS PROFESIONALES RELACIONADOS A LA PROTECCIÓN DEL PATRIMONIO CULTURAL

\section{La ciudadanía y la defensa del patrimonio cultural}

Los estudiantes, profesionales que provienen de diferentes áreas de estudios como arqueólogos, antropólogos, artistas, trabajadores sociales, historiadores del arte, educadores, museólogos,

15 La Lista Roja de bienes culturales peruanos en peligro publicada por el Consejo Internacional de Museos, señala: "...entre el 2004 y 2006 se interceptaron exportaciones ilícitas de más de 5.000 de bienes culturales y naturales. Las excavaciones clandestinas en sitios arqueológicos han aumentado, así como los saqueos y robos en iglesias y museos..."

La Lista Roja presenta una diversidad de bienes en peligro, clasificados por los siguientes períodos: El Prehispánico: Las categorías se subdividen en: Textiles, metales, cerámica, Piedras semipreciosas, Lítico, Madera, Restos Humanos.

En el período Colonial y Republicano, las categorías difieren debido a la influencia del arte y tecnología española: objetos etnográficos, Pinturas, Esculturas, Objetos litúrgicos, Platería, Numismática, Mobiliario, Estampas, Tejidos, Documentos, Cerámica.

Es a través de este instrumento que podemos identificar cuales son las piezas culturales que están en peligro de ser comercializados, y es una ayuda para que la ciudadanía este alerta en el caso puedan reconocer alguna pieza en su localidad dando parte a las autoridades. economistas, administradores, abogados, profesionales de turismo, entre otros pueden intervenir desde su campo de acción para la promoción, incentivo, diseño y realización de proyectos educativos, económicos-sociales, socio-culturales, etnohistóricos, arqueológicos, artísticos, entre otros, relacionados a la defensa y protección del patrimonio cultural, tomando decisiones, y gestionando administrativa, económica, formativa, comunicativa y artísticamente proyectos multidisciplinarios.

Es necesario la sensibilización a la población en temas relacionados a la protección del patrimonio cultural, con un equipo multidisciplinario, que provea información necesaria para que el ciudadano tenga los instrumentos necesarios para hacer frente a esta problemática.

La protección del patrimonio cultural como bien dice el artículo 5 del título preliminar de la Ley 28296, es responsabilidad de todo ciudadano:

Los bienes integrantes del Patrimonio Cultural de la Nación, independientemente de su condición privada o pública, están protegidos por el Estado y sujetos al régimen específico regulado en la presente Ley. El Estado, los titulares de derechos sobre bienes integrantes del Patrimonio Cultural de la Nación y la ciudadanía en general tienen la responsabilidad común de cumplir y vigilar el debido cumplimiento del régimen legal establecido en la presente Ley.

El Estado promoverá la participación activa del sector privado en la conservación, restauración, exhibición y difusión de los bienes integrantes del Patrimonio Cultural de la Nación y su restitución en los casos de exportación ilegal o cuando se haya vencido el plazo de permanencia fuera del país otorgado por el Estado.

\section{Excavaciones clandestinas}

A fin de detener las excavaciones ilegales (saqueos y huaqueos) en las zonas arqueológicas de 
los distritos, se podría trabajar en conjunto con las organizaciones vecinales, sociales y civiles de la comunidad en coordinación con las municipalidades locales, Ente Rector, Policía Nacional, y otros para mejorar la protección, señalización, delimitación de las zonas arqueológicas que permitiría mejorar la seguridad.

Al mismo tiempo coordinar la realización de la puesta en valor con el Ente Rector, que permitiría mejorar el estado de conservación del sitio, y si fuera posible un pequeño museo cercano en las que se exponga los bienes culturales hallados en el sitio.

Se podrían realizar actividades que generen ingresos por medio del turismo y que serían espacios donde los niños y jóvenes podrían conocer de cerca su patrimonio. Casos como estos se pueden observar en la Huaca Pucllana en la que un grupo de arqueólogos en Miraflores emprendió un proyecto cultural "Centro cultural de la Huaca Pucllana ${ }^{16 "}$ que muestra bienes culturales de la zona arqueológica, y actualmente realiza varias actividades en pro de la comunidad como talleres para niños y guiados, asimismo el restaurante ubicado cerca de la Huaca realza con sus espectáculos culturales el sitio arqueológico. Otro gran ejemplo de gestión del patrimonio arqueológico lo tenemos en el Proyecto Arqueológico Caral ${ }^{17}$, que tiene una imagen mundial, y que el nivel turístico en la zona, generando ingresos a las familias de los alrededores, asimismo se ha incrementado levantando la imagen del Perú en el exterior por su valor e importancia arqueológica y social.

\section{Hurtos}

Son las iglesias de pueblos alejados del Perú donde no existen medidas mínimas de seguridad, las que están en peligro de ser robados. Es ahí donde nosotros podríamos comenzar a realizar proyectos

16 Museo de Sitio Parque Histórico Cultural Huaca Pucllana. Accesible en Internet: < http://pucllana.perucultural.org.pe >. [9 de Agosto de 2010].

17 Proyecto Arqueológico Caral Accesible en Internet, $<$ http//:www.caralperu.gob.pe $>$. [7 de Julio de 2010]. de sensibilización a la comunidad fomentado la importancia de la seguridad en ellas, así como la necesidad de emprender la tarea de registro de sus bienes culturales. Lamentablemente el más beneficiado de esta situación es el ladrón, que ve en estas iglesias, un botín de acceso fácil. Veamos el caso del retablo de Challapampa que fue robado de una iglesia en Challapampa en el 2002 aproximadamente, siendo cortado en pequeñas piezas que salieron del país y apareció en EEUU en el 2004, siendo repatriado el 2005 a su pueblo de origen en la ciudad de chuchito - Puno.

\section{Registro}

Seria necesario una campaña de registro de bienes culturales a nivel nacional con énfasis en la difusión por televisión, prensa escrita, para que toda la ciudadanía a través de los museos del país, centros culturales, organizaciones sociales y otros también sean intermediarios en la promoción de la importancia del registro de bienes culturales para la recuperación de los bienes culturales en caso de hurtos o extracciones del país sin autorización.

\section{Legislación}

Podemos integrar equipos de trabajo con políticos, representantes culturales de entidades, artistas para desarrollar el diálogo, y se pueda plantear al congreso recomendaciones para la protección al patrimonio cultural, y presentar proyectos de ley a fin de mejorar las leyes actuales, para esto es necesario contar con un bagaje cultural que nos permita fundamentación sobre las leyes para la protección del patrimonio cultural

\section{Capacitación sobre patrimonio cultural}

Con equipos de trabajo multidisciplinario podemos coordinar con los gobiernos regionales, locales, Ente Rector, colegios, comunidad, entre otros, a fin de llegar hasta el ciudadano que tiene menos recursos, para que tengan conocimiento de su patrimonio cultural. 
A nivel educativo, se podría promover proyectos de mejora curricular e incluir un curso sobre protección al patrimonio cultural, a fin de que los niños, adolescentes y jóvenes se identifiquen con su país y cuiden su patrimonio cultural.

\section{RECOMENDACIONES}

1. A fin de generar ingresos a las comunidades cercanas a las zonas arqueológicas y evitar las invasiones, se podrían proyectar rutas turísticas a fin de poner en valor esas zonas a través de convenios entre estas instituciones a fin de que se haga más viable y rápido

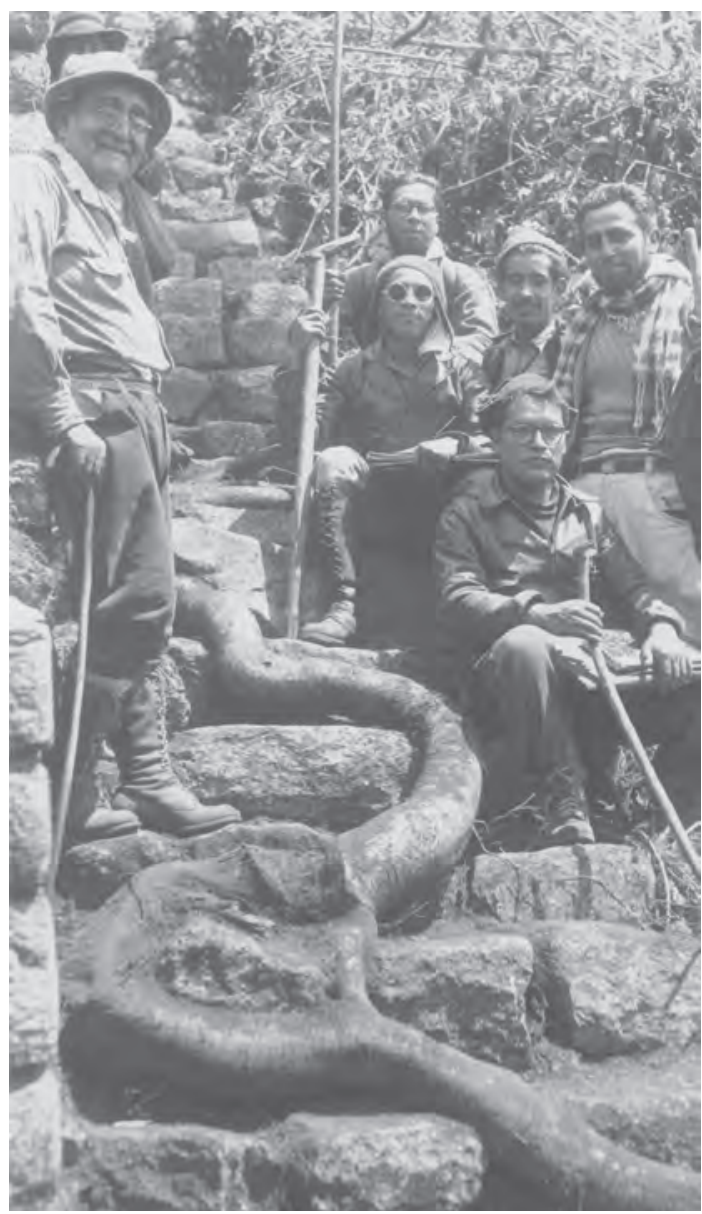

Julio C. Tello con su equipo de trabajo en Wiñay Wayna, Cusco, 1942. Archivo Tello. MAA. UNMSM este proceso.

2. En coordinación con gobiernos locales y regionales, se puede presentar proyectos socio-culturales a nivel de la sociedad civil para instruir a la población en el cuidado de sus bienes culturales.

3. Es a través de los museos, galerías y otros con una adecuada museografía y guiones para el incentivo de niños, jóvenes, adultos un medio por el cual se pueda aprender y conocer nuestro patrimonio cultural, este medio incentiva a la asociación de ideas y a la riqueza cultural del ciudadano.

4. A fin de que personas extranjeras que no son coleccionistas y desconocen el valor de patrimonio cultural de los objetos culturales peruanos, se podría presentar propuestas tales como la instalación de videos educativos en los aviones, ómnibus, barcos, y otros antes de llegar al Perú, así como la entrega en mano de un folleto en el que describa los atentados contra el patrimonio a fin de que antes de comprar bienes culturales y sean estafados, verifiquen su originalidad, y no lo compre. Asimismo en los lugares de información al turista se promocione el cuidado de nuestro patrimonio cultural asi como las formas de actuar del extranjero en caso de una estafa y las responsabilidades que atañe.

5. Se propone la creación de una norma y reglamentación para mercados artesanales, que incluya la previa certificación de autorización del Ente Rector, Municipio, Sunat para la venta de artesanías que no sean pertenecientes al patrimonio cultural, y que sea requisito para la apertura y continuación del establecimiento, de esa manera se obligaría a estos proveedores a que tengan más cuidado en el momento de vender piezas que pueden ser bienes culturales.

6. Interconectar las páginas web de todas las instituciones relacionados a la protección del patrimonio cultural a fin de colocar in- 
formación valiosa y educativa al alcance de todos a fin de que estemos informados de la situación y saber como actuar ante un caso de atentados contra patrimonio cultural.

7. A nivel legal, es necesario que proponer proyectos de Ley al Legislativo para la mejora de toda la legislación peruana en materia de protección del patrimonio cultural.

9. A fin de incentivar la creación de nuevos valores se propone concursos de arte, música, pintura, u otros que tengan de tema la protección del patrimonio cultural con apoyo de empresas privadas o de diferentes instituciones.

10. A nivel de Universidades tanto público como privadas, se propone que los estudiantes de pregrado y postgrado con asesoría de docentes o egresados podrían plantear la creación de una oficina que vele por los asuntos relacionados a la protección de patrimonio cultural que genere proyectos socio culturales a fin de que los estudiantes puedan aplicar sus conocimientos y brinden un servicio a la comunidad universitaria y la ciudadanía en general, asimismo a través de ella se puede coordinar con las diferentes agrupaciones juveniles de música, arte, teatro entre otros de la misma universidad para que este proceso sea aun mas viable.

11. Se recomienda mantener vigilancia las fronteras y mejorar el equipamiento y control en ellas, y contar con presencia de delegaciones del Ente Rector, Aduanas, y otros con las medidas de control oportunas con total transparencia.

12. Asimismo es necesario que a nivel de países latinoamericanos, se solicite formalmente a UNESCO, la ratificación de los países que no están en los Convenios de 1970 y 1972 a fin de poder recuperar nuestros bienes culturales que se encuentran en estos países.

\section{Bibliografía}

Cárdenas Oscátegui, Carolina

2009 "La importancia de la protección del patrimonio cultural mueble en el Perú". En Revista Anual Tesis. UNMSM. Unidad de Postgrado de la Facultad de Letras. Vol. № 03. Año III.

Carrillo Carrillo, Beatriz.

2001 "Tráfico internacional de bienes culturales y derecho internacional privado". Anales de Derecho, № 9, pp. 205-234. Universidad de Murcia, España.

Castelli González, Amalia

2003 Situación actual del tráfico ilícito del patrimonio de bienes culturales.

Alva, Walter; De Trazegnies, Fernando; Lumbreras, Luis; et al.

2000 Patrimonio Cultural del Perú I. Congreso de la Republica del Perú.

ICOM

2003 Lista Roja de bienes culturales peruanos en peligro. Paris. ICOM

INC

2009 Revista Gaceta Cultural. Abril, № 37 Lima- Perú.

2006 Casos de Gestión Cultural en el Perú. OEI. Perú.

2003 Taller regional de lucha contra el tráfico ilícito de biesnes culturales. Perú,

Martorell Carreño, Alberto.

1969 Patrimonio cultural: Protegiendo nuestras raíces. Un estudio de derecho cultural. BNP. Lima.

Paz Cabello, Maria; Bakula, Cecilia

2007 Patrimonio, cultura e identidad. Madrid. Ministerio de Cultura. 2007

Pernille, Askerud; Etienne, Clément

1999 La Prevención del Tráfico Ilícito de Bienes Culturales: Un Manual de la Unesco para la implementación de la Convención de 1970. Unesco.

Rivera Díaz, Johana

2004 Robo y tráfico de bienes culturales. Chile. Tesis para optar a la Licenciatura de Teoría e Historia del Arte. Universidad de Chile. 


\section{UNESCO}

1984 Compendium of legislative text. The protection of movable cultural property. Francia. Ed. United Nations Educational.

1968 La preservation des biens culturels. Francia. Ed. United Nations Educational.

\section{Páginas Web}

Cárdenas Oscátegui, Carolina. "La protección y conservación del patrimonio cultural en Latinoamérica". Publicado en EBAM. $<$ http://ebam.gesbi.com.ar/reservorio10/ ponencias2EBAM/2EBAM-E3-p7a.pdf>. [5 de octubre de 2010].

Castillo Calderón Andrea. "Robo de bienes culturales del país en aumento en el último año". El Comercio. <http://www.elcomercio.com.pe/ edicionimpresa/html/2008-04-04/robo-bienesculturales-pais-aumento-ultimo-ano.html >, [7 de marzo de 2009].

Comisión Andina de Fomento. "Normatividad Andina. Decisión 588". <http://www.comunidadandina.org/normativa/dec/D588.htm > , [5 de Junio de 2009].

Cusco Web. "Perú elabora lista roja de bienes culturales para protegerlos de traficantes". $<$ http://www.cuscoweb.com/noticias/detalles. php?d=5646>, [25 de Junio de 2009].

El Comercio. "Tráfico de piezas históricas peruanas alcanza niveles nunca vistos, según expertos". <http://www.elcomercio.com.pe/ediciononline/html/2009-01-13/trafico-piezas-históricas-peruanas-alcanza-niveles-nunca-vistossegún-expertos.html>, [5 de Junio de 2009].

ICOM. "El tráfico ilícito del patrimonio cultural". <http://www.international.icomos.org/ home.htm $>$.

ICOM. Lista Roja Latinoamérica. "Legislación para la protección del patrimonio". <http:// www.icom.museum/redlist/LatinAmerica/spanish/legislation.html>, [6 de Junio de 2009].

INC. "Compendio de Normas Legales Nacionales de Protección al Patrimonio Cultural de la Nación". <http://www.inc.gob.pe/serv24.sht$\mathrm{ml}>$, [6 de Junio de 2009].

INTERPOL. "Obras de arte robadas". < http:// www.interpol.int/Public/WorkOfArt/DefaultEs. asp>, [2 de Julio de 2009].

Marquis, Diego. "Presentación de campaña de lucha contra el tráfico ilícito de bienes culturales, en el marco de las 11 Jornadas Universitarias de Relaciones Públicas organizadas junto a la Revista Imagen. El tráfico ilícito de bienes culturales ocupa el tercer lugar en el ranking mundial de mercados ilegales". $<$ http://www.fido.palermo.edu/servicios dyc/noticiasdc/detalle.php?id noticia $=340>$, $[8 \overline{\mathrm{de}}$ abril de 2009].

Ministerio de Relaciones Exteriores. "Plan de política cultural del Perú en el exterior". $<$ http://www.rree.gob.pe/portal/enlaces.nsf/3fo 8cf720c1dbf4805256de20052913d/06f3677c8 f3beac805257597006f99eb/\$FILE/PlanPolCu1ExtFin.pdf>, [4 de Julio de 2009].

La República. "El 2008 lograron impedir salida ilegal del país de 1,235 bienes culturales". < http:// www.larepublica.pe/sociedad/28/01/2009/el-2008lograron-inmovilizar-1-235-bienes-culturales-impidiendo-su-salida-ilegal >, [1 de Julio de 2009].

Portal Iberoamericano de Gestión Cultural. "Es la gestión cultural una profesión”. <http://www. gestioncultural.org/gc/>, [2 de junio de 2009]. Shady Solís, Ruth. "Política Cultural en el Perú y la Situación del Patrimonio Arqueológico". Int. J.S. AM archaeolog 2: 6-17. <http://www.scribd. com/doc/7338024/Politica-Cultural-en-el-Peruy-la-Situacion-del-Patrimonio-Arqueologico $>$, [2 de junio de 2009].

UNESCO. "Bienes culturales: su tráfico ilícito y su restitución. Documentos Normativos". <http://www.portal.unesco.org/culture/ es/ev.phpURL_ID $=35252 \& U R L \_D O=D O$ TOPIC\&URL SECTION $=201 . \mathrm{html}>, \quad[5 \mathrm{de}$ Junio de 2009].

U.S. State Department. Bureau of educational and cultural affairs. "Internacional cultural property protection". <http://www.culturalheritage.state.gov/1pe97agr.html>, [6 de Junio de 2009]. 